\title{
AVALIAÇÃO DE DANOS CAUSADOS POR PERCEVEJOS E POR LAGARTAS EM GENÓTIPOS DE SOJA DE CICLOS PRECOCE E SEMIPRECOCE ${ }^{1}$
}

\author{
ANDRÉ LUIZ LOURENÇÃO², JOSÉ CARLOS VILA NOVA ALVES PEREIRA ${ }^{3}$, \\ MANOEL ALBINO COELHO DE MIRANDA ${ }^{4}$ e GLÁUCIA MARIA BOVI AMBROSANO ${ }^{5}$
}

\begin{abstract}
RESUMO - Avaliaram-se os danos causados por percevejos e lagartas em cultivares e linhagens de soja de ciclos precoce e semiprecoce, em experimentos instalados em campo, na Estação Experimental de Ribeirão Preto (Instituto Agronômico, SP), nos anos agrícolas 1995/96 e 1996/97. A infestação de percevejos, com predominância de Piezodorus guildinii (West.), foi mais intensa no primeiro ano. Lagartas de Anticarsia gemmatalis Hüb. ocorreram na área experimental apenas no primeiro ano. Nos genótipos de ciclo precoce (110 dias) ('IAS 5', 'IAC 17', IAC 90-3395, IAC 93-345, IAC 93-386), o desfolhamento causado por $A$. gemmatalis variou de $11,7 \%$ ('IAC 17 ') a $28,3 \%$ (IAC 90-3395). Os danos causados por percevejos foram avaliados por meio de três critérios: retenção foliar, danos nas vagens e produção. As linhagens IAC 93-345, IAC 93-386 e IAC 90-3395 e a cultivar IAC 17 apresentaram os menores valores de retenção foliar e de danos nas vagens, com produção significativamente superior à da 'IAS 5' no primeiro ano. Na avaliação do germoplasma semiprecoce (120 dias) ('IAC 15', 'IAC 18', 'IAC 100', IAC 93-2277, IAC 93-2738, IAC 93-3335), a cultivar IAC 100 e a linhagem IAC 93-3335 comportaram-se como resistentes a $A$. gemmatalis, e a cultivar IAC 15 , como suscetível a essa lagarta e aos percevejos. 'IAC 18' teve produção estável nos dois anos, aproximadamente $600 \mathrm{~g} / 3 \mathrm{~m}$ de linha, comparável às maiores médias, embora apresentasse os maiores índices de retenção foliar. Entre as linhagens, IAC 93-3335 foi menos danificada por lagartas, assim como apresentou menos danos nas vagens e produção similar à da cultivar IAC 18.
\end{abstract}

Termos para indexação: Glycine max, resistência a pragas, insetos, Pentatomidae, Anticarsia gemmatalis, dano às vagens.

\section{EVALUATION OF DAMAGE TO EARLY MATURITY SOYBEAN CULTIVARS AND LINES CAUSED BY STINK BUGS AND CATERPILLARS}

\begin{abstract}
The damage of stink bugs and caterpillars was evaluated in soybean cultivars and lines from two maturity groups, in experiments under field conditions, at the Instituto Agronômico, in the Experimental Station of Ribeirão Preto, SP, Brazil, in the 1995/96 and 1996/97 seasons. The stink bug infestation, predominantly Piezodorus guildinii (West.), was more intense in the first season. Anticarsia gemmatalis Hüb. infested the experiments only in the first year. Among the early maturing genotypes with approximately 110 days ('IAS 5', 'IAC 17', IAC 90-3395, IAC 93-345 and IAC 93-386), the cultivar IAC 17 showed the lowest defoliation (11.7\%) caused by A. gemmatalis, while the line IAC 90-3395 presented the highest (28.3\%). Regarding to the stink bug damage, as evaluated by three criteria (foliar retention, pod damage and yield), the lines IAC 93-345, IAC 93-386 and IAC 90-3395 and the cultivar IAC 17 presented the highest resistance levels, yielding more than cultivar IAS 5, in the first year. Among the genotypes of 120-days maturity group ('IAC 15', 'IAC 18', 'IAC 100', IAC 93-2277, IAC 93-2738, IAC 93-3335), the cultivar IAC 100 and the line IAC 93-3335 were the most resistant to A. gemmatalis. The cultivar IAC 15 was susceptible to that insect and to the stink bugs. The cultivar IAC 18 ranked as one of the highest yielding genotypes in spite of its high foliar retention, maintaining stable average yields over years. Among the lines, IAC 93-3335 showed the lowest defoliation by A. gemmatalis, and presented low pod damage and good yield, similar to cultivar IAC 18.
\end{abstract}

Index terms: Glycine max, host plant resistance, insecta, Pentatomidae, Anticarsia gemmatalis, pod damage.

\footnotetext{
${ }^{1}$ Aceito para publicação em 23 de julho de 1999.

${ }^{2}$ Eng. Agrôn., Dr., Instituto Agronômico (IAC), Caixa Postal 28, CEP 13001-970 Campinas, SP. Bolsista do CNPq E-mail: andre@cec.iac.br
}

\footnotetext{
${ }^{3}$ Eng. Agrôn., IAC.

${ }^{4}$ Eng. Agrôn., Dr., IAC.

${ }^{5}$ Eng. Agrôn., Dr., Universidade Estadual de Campinas (UNICAMP), Caixa Postal 52, CEP 13414-018 Piracicaba SP. E-mail: glaucia@fop.unicamp.br
} 


\section{INTRODUÇÃO}

Tanto ecológica como economicamente, resistência de plantas é uma tática de controle de pragas desejável, uma vez que é compatível com outros métodos de controle, como químico, microbiano, cultural, e freqüentemente exibe efeitos sinergísticos com inseticidas e com inimigos naturais (Kogan, 1989). No programa de melhoramento de soja do Instituto Agronômico (IAC), para introdução de fatores de resistência a insetos, foram utilizadas inicialmente as introduções PI 171451, PI 227687 e PI 229358, com resistência múltipla (Duyn et al., 1971; Clark et al., 1972; Luedders \& Dickerson, 1977), PI 274453 e PI 274454, com resistência a Omiodes indicata (Fabr.) (Lepidoptera: Pyralidae) (Lourenção et al., 1985) e a percevejos fitófagos pentatomídeos (Rossetto et al., 1986).

Todavia, essas introduções apresentam características agronômicas desfavoráveis, como, principalmente, arquitetura inadequada da planta, ciclo muito longo e sementes de tamanho e coloração indesejáveis. Dessa forma, após hibridações com germoplasmas resistentes, selecionaram-se linhagens avançadas portadoras de resistência tanto a percevejos como a desfolhadores, obtendo-se, entre outras linhagens, IAC 73-228, resistente a percevejos (Miranda et al., 1979) e a O. indicata (Lourenção et al., 1985), e IAC 78-2318, com resistência múltipla a insetos (Lourenção \& Miranda, 1987). A cultivar IAC 100 , resistente a percevejos e a desfolhadores (Rossetto, 1989), foi selecionada a partir de cruzamento entre IAC 12 e IAC 78-2318.

Assim, na evolução desse programa, nas hibridações realizadas, substituíram-se as introduções resistentes e selvagens por linhagens avançadas com resistência a insetos (Lourenção et al., 1997). A partir da geração $F_{2}$, em condições de campo, são feitas observações do desfolhamento das plantas causado por coleópteros e lagartas e dos danos causados por percevejos (retenção foliar, vagens do topo da planta muito danificadas), visando eliminar material altamente suscetível a esses insetos.

Em todo processo de seleção, deve-se priorizar alguns fatores, como resistência ao cancro-da-haste - doença fúngica causada por Diaporthe phaseolorum f. sp. meridionalis, que é limitante para o cultivo de soja em várias regiões produtoras do país (Yorinori, 1990) - e resistência a nematóides e a bactérias. Isso dificulta o direcionamento de seleção exclusiva para obtenção de material resistente a insetos.

Há, portanto, necessidade de efetuar estudos detalhados das linhagens mais avançadas e com boas características agronômicas quanto à resistência a insetos, principalmente percevejos, o que constitui o objetivo deste trabalho.

\section{MATERIAL E MÉTODOS}

Dois experimentos envolvendo genótipos de ciclos precoce e semiprecoce foram instalados na Estação Experimental de Ribeirão Preto, SP, pertencente ao IAC, no ano agrícola 1995/96 e repetidos em 1996/97. As datas de semeadura foram 22/11/95 e 11/11/96. Nos dois experimentos, o delineamento experimental utilizado foi o de blocos ao acaso, com seis repetições. No experimento de ciclo precoce, foram estudados cinco tratamentos e, no de ciclo semiprecoce, seis. As parcelas constaram de três linhas de $3 \mathrm{~m}$, com espaçamento de $0,5 \mathrm{~m}$ entre linhas. A adubação foi feita no sulco, de acordo com as necessidades verificadas pela análise de solo. Após desbaste, as linhas ficaram com estande aproximado de 20 plantas $/ \mathrm{m}$. Durante todo o ciclo das plantas não foi feita aplicação de inseticidas. Os tratamentos (cultivares e linhagens) e suas origens estão relacionados na Tabela 1. No grupo precoce, utilizaram-se as cultivares IAS 5 e IAC 17 como padrões suscetível e resistente, respectivamente, mais as linhagens avançadas IAC 90-3395, IAC 93-345 e IAC 93-386, que têm como parentais linhagens descendentes de cruzamentos envolvendo as introduções PI resistentes a insetos. No grupo semiprecoce, foram testados 'IAC 100' (testemunha resistente), 'IAC 15' e 'IAC 18' (padrões de produtividade), e as linhagens avançadas IAC 93-2277, IAC 93-2738 e IAC 93-3335, também descendentes de linhagens resistentes.

Avaliou-se o grau de desfolhamento causado por lagartas de Anticarsia gemmatalis Hüb., estimando-se visualmente, em cada parcela, a porcentagem de área foliar cortada (PAFC). Três critérios foram utilizados para avaliação do dano por percevejos: a) índice porcentual de dano na vagem (IPDV), obtido mediante o exame de cem vagens colhidas no terço médio de 20 plantas tomadas ao acaso na linha central da parcela após sua maturação (Rossetto et al., 1986); b) porcentagem de retenção foliar (PRF), obtida mediante estimativa visual do porcentual de plantas em toda parcela com sintomas de retenção ou haste verde; 
c) produção, relativa à linha central, em que foram considerados apenas os grãos tipos 1 e 2 segundo Jensen \& Newsom (1972), que se referem à ausência de danos visíveis ou apenas com puncturas denotando a alimentação de percevejos mas sem deformações. Para análise estatística, os valores obtidos de PAFC, PRF e IPDV foram transformados em arco seno $\sqrt{x / 100}$, e os de produção, utilizados sem transformação. Efetuaram-se análise de variância e análise conjunta, sendo as médias comparadas pelo teste de Tukey a $5 \%$ de probabilidade.

\section{RESULTADOS E DISCUSSÃO}

\section{Experimento de ciclo precoce}

No ano agrícola 1995/96, lagartas de $A$. gemmatalis ocorreram na área experimental no início de fevereiro, quando as plantas se encontravam no estádio R5, que se refere ao início de enchimento de grãos (Fehr \& Caviness, 1977). 'IAS 5' e IAC 90-3395 foram as mais danificadas, apresentando $27,5 \%$ e $28,3 \%$ de desfolhamento, respectivamente, diferindo significativamente do restante dos genótipos testados (Tabela 2). Embora sem diferir de IAC 93-345, 'IAC 17' apresentou o menor desfolhamento, destacando-se como o material menos danificado por insetos

TABELA 1. Genealogia das cultivares e linhagens de soja de ciclos precoce e semiprecoce avaliadas em campo quanto à resistência a percevejos e desfolhadores, em Ribeirão Preto, SP, nos anos agrícolas 1995/96 e 1996/97.

\begin{tabular}{lll}
\hline Ciclo & \multicolumn{1}{c}{$\begin{array}{c}\text { Cultivar/ } \\
\text { linhagem }\end{array}$} & Genealogia \\
\hline Precoce & 'IAS 5' & 'Hill' x ('Roanoke' x 'Ogden') \\
& 'IAC 17' & D 72-9601-1 X 'IAC 8' \\
& IAC 90-3395 & IAC 77-655 X IAC 82-3413 \\
& IAC 93-345 & 'BR-6' X IAC 83-23 \\
& IAC 93-386 & 'BR-6' X IAC 83-23 \\
\hline Semiprecoce & 'IAC 15' & IAC 77- 3086 X 'Paraná' \\
& 'IAC 100' & 'IAC 12' X IAC 78-2318 \\
& 'IAC 18' & D 72-9601-1 X 'IAC 8' \\
& IAC 93-2277 & IAC 83-46 X IAC 82-3413 \\
& IAC 93-2738 & IAC 80-1177 X IAC 82-3066 \\
& IAC 93-3335 & IAC 80-1177 X IAC 83-288 \\
\hline
\end{tabular}

desfolhadores. Todavia, em experimento realizado no Centro Experimental de Campinas (IAC), em 1993/94, 'IAC 17' não diferiu de 'IAS 5' em relação a essa lagarta (Lourenção et al., 1997), o que provavelmente ocorreu pela menor infestação observada naquela ocasião, proporcionando menor pressão sobre o germoplasma estudado.

A interação ano-tratamento foi significativa com relação a percevejos quanto aos critérios PRF e produção (Tabela 2), o que pode ser atribuído a variações climáticas associadas à maior infestação de percevejos em 1995/96. Nesse ano agrícola, a partir do início de formação de vagens, percevejos pentatomídeos infestaram a gleba experimental, ultrapassando o nível de dano econômico, que é de dois percevejos por metro linear (Gazzoni et al., 1988), e permanecendo acima desse nível até a colheita. Piezodorus guildinii (West.) foi a espécie predominante, sendo observados alguns exemplares de Edessa sp. e de Euschistus heros (Fabr.). Em

TABELA 2. Médias de porcentagem de área foliar cortada (PAFC) por lagartas de Anticarsia gemmatalis e de porcentagem de retenção foliar (PRF) causada por percevejos em três linhagens e duas cultivares de soja de ciclo precoce em condições de infestação natural. Ribeirão Preto, SP, $1995 / 96$ e $1996 / 97^{1}$.

\begin{tabular}{lccccc}
\hline $\begin{array}{l}\text { Cultivar/ } \\
\text { linhagem }\end{array}$ & PAFC & & \multicolumn{3}{c}{ PRF } \\
\cline { 2 - 3 } \cline { 5 - 6 } \cline { 5 - 6 } & $1995 / 96$ & & $1995 / 96$ & $1996 / 97$ & Média \\
\hline \multirow{2}{*}{ 'IAS 5' } & $27,5 \mathrm{a}$ & & $98,3 \mathrm{a}$ & $54,2 \mathrm{a}$ & 76,2 \\
'IAC 17' & $11,7 \mathrm{c}$ & & $7,5 \mathrm{c}$ & $6,7 \mathrm{~b}$ & 7,1 \\
IAC 90--3395 & $28,3 \mathrm{a}$ & & $19,2 \mathrm{bc}$ & $28,3 \mathrm{ab}$ & 23,7 \\
IAC 93-345 & $15,8 \mathrm{bc}$ & & $43,3 \mathrm{~b}$ & $7,5 \mathrm{~b}$ & 25,4 \\
IAC 93-386 & $20,8 \mathrm{~b}$ & & $46,5 \mathrm{~b}$ & $18,3 \mathrm{ab}$ & 32,4 \\
\hline Média & 20,8 & & $43,0 \mathrm{~A}$ & $23,0 \mathrm{~B}$ & 33,0 \\
C.V. $(\%)$ & 9,3 & 26,8 & 57,0 & 43,8 \\
$\mathrm{~s}(\mathrm{~m})^{2}$ & & 6,55 & 5,12 & 4,32 \\
\hline
\end{tabular}

1 Médias seguidas de mesma letra, minúscula na coluna e maiúscula na linha, não diferem significativamente entre si pelo teste de Tukey a 5\% de probabilidade.

${ }^{2}$ Erro-padrão da média. 
1996/97, novamente $P$. guildinii foi a espécie predominante, porém, em populações inferiores, somente atingindo o nível de dano econômico quando as plantas encontravam-se no estádio R6, ou seja, no máximo volume dos grãos. No primeiro ano, enquanto 'IAS 5', padrão suscetível, teve retenção foliar próxima a $100 \%$, diferindo significativamente dos demais genótipos e, assim, confirmando sua suscetibilidade a percevejos (Rossetto et al., 1986; Lourenção et al., 1997), 'IAC 17' exibiu a menor média de PRF (7,5\%), comportando-se de modo semelhante ao observado por Lourenção et al. (1997), em experimento realizado nessa mesma localidade em 1994/95. As linhagens IAC 93-386, IAC 93-345 e IAC 90-3395 tiveram PRF intermediário, das quais a última não diferiu de 'IAC 17'. No ano seguinte, 'IAS 5' novamente apresentou PRF médio maior, embora em níveis bem inferiores aos de 1995/96, diferindo apenas de IAC 93-345 e 'IAC 17', as quais apresentaram índices $7,5 \%$ e $6,7 \%$, respectivamente. A média geral de PRF de 1996/97 foi praticamente a metade da de 1995/96, indicando um efeito menos severo dos percevejos sobre o germoplasma avaliado, em virtude da menor infestação.

A PRF da 'IAS 5' em 1996/97 (54,2\%) é elevada, considerando-se que as populações de percevejos permaneceram abaixo do nível de dano até o estádio R6, embora a espécie predominante fosse P. guildinii, que, segundo Sosa-Gomez \& Moscardi (1995), é a que apresenta maior capacidade de induzir retenção foliar na soja. Sabe-se que, além de percevejos, outros fatores podem induzir retenção foliar, como deficiência de potássio (Mascarenhas et al., 1987), ausência de vagens na planta (Hicks \& Pendleton, 1969), seca na floração ou no período de desenvolvimento de vagens, e excesso de umidade no período de maturação (Sosa-Gomez \& Moscardi, 1995). Como se fez análise do solo da área experimental com posterior adubação de acordo com as necessidades da cultura, deduz-se que não houve problemas com o potássio, e que essa anomalia fisiológica ocorreu por causa de um dos demais fatores que a condicionam ou mesmo de uma combinação deles.

Não houve interação ano-tratamento quanto ao IPDV (Tabela 3). A linhagem IAC 93-345 e a cultivar IAC 17 diferiram da IAS 5, o genótipo com a maior média de danos nas vagens. Embora sem diferirem de 'IAS 5', as linhagens IAC 90-3395 e IAC 93-386 apresentaram IPDV médio intermediário.

Interação significativa ano-tratamento foi verificada no critério produção. No primeiro ano, em virtude de a infestação de percevejos ultrapassar o nível de dano econômico na fase reprodutiva da soja, a produção foi negativamente afetada; todavia, apenas 'IAS 5 ' produziu significativamente menos que os demais genótipos (Tabela 4). Nesse ano, a média geral foi de $372,9 \mathrm{~g} / 3 \mathrm{~m}$ de linha. No ano seguinte, a média foi cerca de $50 \%$ mais elevada $(560,2 \mathrm{~g} / 3 \mathrm{~m}) \mathrm{e}$ os tratamentos não diferiram entre si, embora as linhagens IAC 93-386 e IAC 93-345 tenham produzido acima de $600 \mathrm{~g} / 3 \mathrm{~m}$, esta última com bom desempenho em relação ao IPDV. Verificou-se que, em condição de alta infestação de percevejos, as linhagens IAC e a cultivar IAC 17 apresentaram produção comparável e acima de $400 \mathrm{~g} / 3 \mathrm{~m}$, enquanto 'IAS 5' sofreu forte redução na produção. À medida que diminuiu a infestação de percevejos (ano 1996/97), 'IAS 5' melhorou sua produção, porém produzindo aproxi-

TABELA 3. Médias do índice porcentual de dano na vagem (IPDV) em três linhagens e duas cultivares de soja de ciclo precoce, submetidas a infestação natural de percevejos. Ribeirão Preto, SP, 1995/96 e 1996/971.

\begin{tabular}{|c|c|c|c|}
\hline \multirow{2}{*}{$\begin{array}{l}\text { Cultivar/ } \\
\text { linhagem }\end{array}$} & \multicolumn{3}{|c|}{ IPDV } \\
\hline & $1995 / 96$ & $1996 / 97$ & Média \\
\hline & \multicolumn{3}{|c|}{ - } \\
\hline 'IAS-5' & 25,5 & 30,1 & $27,8 \mathrm{a}$ \\
\hline 'IAC 17' & 17,6 & 18,2 & $17,9 b$ \\
\hline IAC $90-3395$ & 19,5 & 23,0 & $21,2 \mathrm{ab}$ \\
\hline IAC 93-345 & 14,9 & 19,2 & $17,0 \mathrm{~b}$ \\
\hline IAC 93-386 & 20,5 & 20,8 & $20,6 \mathrm{ab}$ \\
\hline Média & $19,6 \mathrm{~A}$ & $22,3 \mathrm{~A}$ & 20,9 \\
\hline C.V. $(\%)$ & & & 19,0 \\
\hline $\mathrm{s}(\mathrm{m})^{2}$ & 1,86 & 1,23 & 1,12 \\
\hline
\end{tabular}

${ }^{1}$ Médias seguidas de mesma letra, minúscula na coluna e maiúscula na linha, não diferem significativamente entre si pelo teste de Tukey a 5\% de probabilidade.

2 Erro-padrão da média. 
madamente $100 \mathrm{~g}$ a menos que IAC 93-386 e IAC 93-345.

As linhagens IAC 93-345 e IAC 93-386 são derivadas de cruzamentos entre a cultivar BR-6 e a linhagem IAC 83-23 (Tabela 1). Esta última, por sua vez, originou-se a partir de cruzamento entre D 72-9601-1 e 'IAC 8', os mesmos ancestrais da cultivar IAC 17, portadora de resistência moderada a percevejos (Lourenção et al., 1997). Essas origens comuns às duas linhagens e à 'IAC 17' podem explicar seu comportamento de resistência a percevejos em relação a 'IAS 5'. A terceira linhagem, IAC 90-3395, descende de IAC 77-655, que tem em sua genealogia a PI 227687, resistente a percevejos. Embora não direcionado exclusivamente para resistência a insetos, o programa de melhoramento de soja do IAC tem como diretrizes o uso de linhagens com resistência a insetos em suas hibridações e a eliminação, sempre que possível, durante as etapas de seleção, de material altamente suscetível a desfolhadores e a percevejos, o que tem contribuído para a obtenção de linhagens com graus variáveis de resistência a insetos.

TABELA 4. Médias de produção de três linhagens e duas cultivares de soja de ciclo precoce, submetidas a infestação natural de percevejos. Ribeirão Preto, SP, 1995/96 e 1996/971.

\begin{tabular}{lccc}
\hline \multirow{2}{*}{$\begin{array}{l}\text { Cultivar/ } \\
\text { linhagem }\end{array}$} & \multicolumn{3}{c}{ Produção } \\
\cline { 2 - 4 } & $1995 / 96$ & $1996 / 97$ & Média \\
\hline & $----------------(g / 3 \mathrm{~m})-------------$ \\
'IAS 5' & $172,8 \mathrm{~b}$ & $505,8 \mathrm{a}$ & 339,3 \\
'IAC 17' & $412,8 \mathrm{a}$ & $506,7 \mathrm{a}$ & 459,7 \\
IAC 90-3395 & $436,8 \mathrm{a}$ & $564,2 \mathrm{a}$ & 500,5 \\
IAC 93-345 & $407,5 \mathrm{a}$ & $604,2 \mathrm{a}$ & 505,8 \\
IAC 93-386' & $434,7 \mathrm{a}$ & $620,0 \mathrm{a}$ & 527,4 \\
\hline Média & $372,9 \mathrm{~B}$ & $560,2 \mathrm{~A}$ & 466,5 \\
$\mathrm{C} . \mathrm{V} .(\%)$ & 20,6 & 15,5 & 17,9 \\
$\mathrm{~s}(\mathrm{~m})^{2}$ & 24,65 & 16,30 & 19,05 \\
\hline
\end{tabular}

1 Médias seguidas de mesma letra, minúscula na coluna e maiúscula na linha, não diferem significativamente entre si pelo teste de Tukey a 5\% de probabilidade.

2 Erro-padrão da média.

\section{Experimento de ciclo semiprecoce}

Como este experimento e o de ciclo precoce foram instalados lado a lado, as infestações de insetos foram semelhantes. A intensidade de infestação de A. gemmatalis, similar à do experimento de ciclo precoce, também permitiu detectar diferenças no comportamento do germoplasma. As menores médias de PAFC foram verificadas em 'IAC 100' - ratificando sua resistência a esse inseto (Oliveira et al., 1993; Hoffmann-Campo et al., 1994; Castiglioni \& Vendramim, 1996) - e na linhagem IAC 93-3335, ambas com 17,5\% (Tabela 5). As cultivares IAC 15 e IAC 18 e a linhagem IAC 93-2277 tiveram as maiores perdas foliares, diferindo significativamente de 'IAC 100' e de IAC 93-3335.

Ao contrário do experimento de ciclo precoce, com a utilização do critério PRF, a interação ano-tratamento não foi significativa. A maior infestação dos percevejos no primeiro ano ficou evidente ao se com-

TABELA 5. Médias de porcentagem de área foliar cortada (PAFC) por lagartas de Anticarsia gemmatalis e de porcentagem de retenção foliar (PRF) causada por percevejos em três linhagens e três cultivares de soja de ciclo semiprecoce em condições de infestação natural. Ribeirão Preto, SP, 1995/96 e 1996/971.

\begin{tabular}{|c|c|c|c|c|}
\hline \multirow{2}{*}{$\begin{array}{l}\text { Cultivar/ } \\
\text { linhagem }\end{array}$} & \multirow{2}{*}{$\frac{\text { PAFC }}{1995 / 96}$} & \multicolumn{3}{|c|}{ PRF } \\
\hline & & $1995 / 96$ & $1996 / 97$ & Média \\
\hline & --- & -- & $\%)--$ & ---- \\
\hline 'IAC 15' & $31,7 \mathrm{a}$ & 41,7 & 7,5 & $24,6 \mathrm{ab}$ \\
\hline 'IAC 18' & $28,3 \mathrm{a}$ & 45,0 & 14,2 & $29,6 \mathrm{a}$ \\
\hline 'IAC 100' & $17,5 b$ & 21,7 & 10,8 & $16,2 \mathrm{ab}$ \\
\hline IAC 93-2277 & $28,3 \mathrm{a}$ & 7,5 & 1,7 & $4,6 c$ \\
\hline IAC 93-2738 & $26,7 \mathrm{ab}$ & 6,7 & 0,8 & $3,7 \mathrm{c}$ \\
\hline IAC 93-3335 & $17,5 b$ & 28,3 & 3,3 & $15,8 b$ \\
\hline Média & 25,0 & $25,1 \mathrm{~A}$ & $6,4 \mathrm{~B}$ & 15,7 \\
\hline C.V. $(\%)$ & 12,8 & & & 43,3 \\
\hline $\mathrm{s}(\mathrm{m})^{2}$ & & 3,48 & 1,15 & 2,13 \\
\hline
\end{tabular}


parar as médias dos tratamentos entre anos: $25,1 \%$ no primeiro e $6,4 \%$ no segundo (Tabela 5 ). Considerando-se a média dos dois anos para cada tratamento, as linhagens IAC 93-2277 e IAC 93-2738 destacaram-se pela maturação mais regular. 'IAC 100', cultivar com características de resistência a percevejos, diferiu dessas duas linhagens, apresentando comportamento intermediário, embora sem diferir estatisticamente de 'IAC 18', o tratamento de maior média.

No critério IPDV houve interação ano-tratamento. No primeiro ano, esse critério permitiu separar três grupos de tratamentos: o de menor dano, representado por IAC 93-3335 e 'IAC 100', que diferiu significativamente de 'IAC 15' e de IAC 93-2277, as quais mostraram mais suscetibilidade (Tabela 6). 'IAC 18' e IAC 93-2738 comportaram-se de forma intermediária, porém sem diferirem significativamente dos genótipos considerados resistentes ou suscetíveis. Em 1996/97, novamente IAC 93-3335 e 'IAC 100' sofreram os menores danos nas vagens, diferindo

TABELA 6. Médias do índice porcentual de dano na vagem (IPDV) em três linhagens e três cultivares de soja de ciclo semiprecoce, submetidas a infestação natural de percevejos. Ribeirão Preto, SP, 1995/96 e 1996/97'.

\begin{tabular}{lccc}
\hline $\begin{array}{l}\text { Cultivar/ } \\
\text { linhagem }\end{array}$ & \multicolumn{3}{c}{ IPDV } \\
\cline { 2 - 4 } & $1995 / 96$ & $1996 / 97$ & Média \\
\hline \multirow{2}{*}{ 'IAC 15' } & $25,9 \mathrm{a}$ & $15,8 \mathrm{a}$ & 20,8 \\
'IAC 18' & $17,6 \mathrm{ab}$ & $13,9 \mathrm{ab}$ & 15,7 \\
'IAC 100' & $11,6 \mathrm{~b}$ & $8,4 \mathrm{c}$ & 10,0 \\
IAC 93-2277 & $25,3 \mathrm{a}$ & $10,7 \mathrm{bc}$ & 18,0 \\
IAC 93-2738 & $17,4 \mathrm{ab}$ & $10,2 \mathrm{bc}$ & 13,8 \\
IAC 93-3335 & $13,5 \mathrm{~b}$ & $9,2 \mathrm{c}$ & 11,3 \\
\hline Média & $18,5 \mathrm{~A}$ & $11,4 \mathrm{~B}$ & 14,9 \\
C.V. (\%) & 13,1 & 11,2 & 13,4 \\
s(m) & 1,20 & 0,57 & 0,79 \\
\hline
\end{tabular}

1 Médias seguidas de mesma letra, minúscula na coluna e maiúscula na linha, não diferem significativamente entre si pelo teste de Tukey a 5\% de probabilidade.

2 Erro-padrão da média. de 'IAC 18' e 'IAC 15', que apresentou, a exemplo do ano anterior, a maior média de IPDV.

A interação ano-tratamento foi significativa no critério produção. No primeiro ano, houve discriminação entre os tratamentos, enquanto no segundo, as diferenças não foram significativas. Em 1995/96, 'IAC 15' foi o genótipo menos produtivo, diferindo dos demais, com exceção de 'IAC 100'. A linhagem IAC 93-3335 apresentou a mais alta produção, sendo superior à 'IAC 100' e à 'IAC 15' (Tabela 7). Baseando-se nos dois anos, a linhagem IAC 93-3335 e a cultivar IAC 18 tiveram boas produções, com médias próximas a $600 \mathrm{~g} / 3 \mathrm{~m}$ de linha. O fato de 'IAC 18' ter produção estável em condições de infestações de percevejos, acima e abaixo do nível de dano econômico, sugere que a cultivar seja portadora de tolerância a esses insetos, cujo mecanismo poderia ser a produção de maior número de sementes ou a rejeição de vagens novas danificadas com substituição por novas vagens. Os dados de PAFC e de IPDV da 'IAC 100' confirmam sua resistência a desfolhadores e a percevejos (Rossetto, 1989; Fernandes et al.,

TABELA 7. Médias de produção de três linhagens e três cultivares de soja de ciclo semiprecoce, submetidas a infestação natural de percevejos. Ribeirão Preto, SP, 1995/96 e 1996/971.

\begin{tabular}{lccc}
\hline \multirow{2}{*}{$\begin{array}{l}\text { Cultivar/ } \\
\text { linhagem }\end{array}$} & \multicolumn{3}{c}{ Produção } \\
\cline { 2 - 4 } & $1995 / 96$ & $1996 / 97$ & Média \\
\hline & $----------------(g / 3 \mathrm{~m})-----------------$ \\
'IAC 15' & $357,8 \mathrm{c}$ & $570,8 \mathrm{a}$ & 464,3 \\
'IAC 18' & $594,0 \mathrm{ab}$ & $609,2 \mathrm{a}$ & 601,6 \\
'IAC 100' & $480,8 \mathrm{bc}$ & $540,8 \mathrm{a}$ & 510,8 \\
IAC 93-2277 & $529,0 \mathrm{ab}$ & $515,8 \mathrm{a}$ & 522,4 \\
IAC 93-2738 & $542,7 \mathrm{ab}$ & $508,3 \mathrm{a}$ & 525,5 \\
IAC 93-3335 & $664,0 \mathrm{a}$ & $514,2 \mathrm{a}$ & 589,1 \\
\hline Média & $528,0 \mathrm{~A}$ & $543,2 \mathrm{~A}$ & 535,6 \\
C.V. (\%) & 17,5 & 17,6 & 17,6 \\
s(m) ${ }^{2}$ & 21,60 & 18,53 & 14,16 \\
\hline 1 Médias seguidas de mesma letra, minúscula na coluna e maiúscula na \\
linha, não diferem significativamente entre si pelo teste de Tukey a 5\% \\
de probabilidade. \\
2 Erro-padrão da média.
\end{tabular}


1994; Lourenção et al., 1997), porém os de PRF e de produção situaram-se num patamar inferior ao esperado. Entre as linhagens avançadas, o melhor comportamento foi da IAC 93-3335, que teve desfolhamento comparável ao da cultivar IAC 100, além de baixas médias de IPDV e boa produção.

\section{CONCLUSÕES}

1. Entre os germoplasmas de ciclo precoce, há superioridade das três linhagens quanto à resistência a percevejos, em relação à cultivar IAS 5, destacando-se IAC 93-345, que também apresenta baixa perda foliar, decorrente do ataque de $A$. gemmatalis, comparável à da cultivar resistente IAC 17.

2. No ciclo semiprecoce, a cultivar IAC 18, apesar de ser suscetível a lagartas e de apresentar altas médias de porcentagem de retenção foliar e do índice porcentual de dano na vagem, é produtiva na presença de percevejos; entre as linhagens, IAC 93-3335 se destaca pelos menores índices de danos causados por lagartas e por percevejos e pela alta produtividade.

\section{REFERÊNCIAS}

CASTIGLIONI, E.A.; VENDRAMIM, J.D. Efeitos de genótipos de soja no desenvolvimento de Anticarsia gemmatalis Hübner (Lepidoptera: Noctuidae). Anais da Sociedade Entomológica do Brasil, Londrina, v.25, n.3, p.411-416, 1996.

CLARK, W.J.; HARRIS, F.A.; MAXWELL, F.G.; HARTWIG, E.E. Resistance of certain soybean cultivars to bean leaf beetle, striped blister beetle and bollworm. Journal of Economic Entomology, Lanham, v.65, n.6, p.1669-1672, 1972.

DUYN, J.W. van; TURNIPSEED, S.G.; MAXWELL, J.D. Resistance in soybeans to the Mexican bean beetle. I. Sources of resistance. Crop Science, Madison, v.11, n.4, p.572-573, 1971

FEHR, W.R.; CAVINESS, C.E. Stages of soybean development. Ames : Iowa State UniversityCooperative Extension Service, 1977. 12p. (Special Report, 80).

FERNANDES, F.M.; ATHAYDE, M.L.F.; LARA, F.M. Comportamento de cultivares de soja no campo em relação ao ataque de percevejos. Pesquisa
Agropecuária Brasileira, Brasília, v.29, n.3, p.363367, mar. 1994.

GAZZONI, D.; OLIVEIRA, E.B. de; CORSO, I.C.; FERREIRA, B.S.C.; VILLAS BÔAS, G.L.; MOSCARDI, F.; PANIZZI, A.R. Manejo de pragas da soja. Londrina : Embrapa-CNPSo, 1988. 44p. (Embrapa-CNPSo. Circular Técnica, 5).

HICKS, D.R.; PENDLETON, J.W. Effect of floral bud removal on performance of soybeans. Crop Science, Madison, v.9, n.4, p.435-437, 1969.

HOFFMANN-CAMPO, C.B.; MAZZARIN, R.M.; LUSTOSA, P.R. Mecanismos de resistência de genótipos de soja: teste de não-preferência para Anticarsia gemmatalis Hübner, 1818. (Lep.: Noctuidae). Pesquisa Agropecuária Brasileira, Brasília, v.29, n.4, p.513-519, abr. 1994.

JENSEN, R.L.; NEWSOM, L.D. Effect of stink bugdamaged soybean seeds on germination, emergence and yield. Journal of Economic Entomology, Lanham, v.65, n.1, p.261-264, 1972.

KOGAN, M. Plant resistance in soybean insect control. In: CONFERENCIA MUNDIAL DE INVESTIGACIÓN EN SOJA, 4., 1989, Buenos Aires. Actas. Buenos Aires : Orientación Gráfica Editora SRL, 1989. v.3, p.1519-1525.

LOURENÇÃO, A.L.; MIRANDA, M.A.C. de; PEREIRA, J.C.V.N.A.; AMBROSANO, G.M.B. Resistência de soja a insetos. X. Comportamento de cultivares e linhagens em relação a percevejos e desfolhadores. Anais da Sociedade Entomológica do Brasil, Londrina, v.26, n.3, p.543-550, 1997.

LOURENÇÃO, A.L.; MIRANDA, M.A.C. de. Resistência de soja a insetos. VIII. IAC 78-2318: linhagem com resistência múltipla. Bragantia, Campinas, v.46, n.1, p.65-72, 1987.

LOURENÇÃO, A.L.; ROSSETTO, C.J.; MIRANDA, M.A.C. de. Resistência de soja a insetos. IV. Comportamento de cultivares e linhagens em relação a Hedilepta indicata (Fabr.). Bragantia, Campinas, v.44, n.1, p.149-157, 1985.

LUEDDERS, V.D.; DICKERSON, W.A. Resistance of selected soybean genotypes and segregating populations to cabbage looper feeding. Crop Science, Madison, v.17, n.3, p.395-397, 1977.

MASCARENHAS, H.A.A.; MIRANDA, M.A.C. de; LELIS, L.G.L.; BULISANI, E.A.; BRAGA, N.R.; PEREIRA, J.C.V.N.A. Haste verde e retenção 
foliar em soja por deficiência de potássio. Campinas : Instituto Agronômico, 1987. 15p. (Instituto Agronômico. Boletim Técnico, 119).

MIRANDA, M.A.C. de; ROSSETTO, C.J.; ROSSETTO, D.; BRAGA, N.R; MASCARENHAS, H.A.A.; TEIXEIRA, J.P.F.; MASSARIOL, A. Resistência de soja a Nezara viridula e Piezodorus guildinii em condições de campo. Bragantia, Campinas, v.38, p.181-188, 1979.

OLIVEIRA, L.J.; HOFFMANN-CAMPO, C.B.; MAZZARIN, R.M. Aspectos biológicos e nutricionais de Anticarsia gemmatalis Hüb. (Lepidoptera: Noctuidae) em diversos genótipos de soja. Anais da Sociedade Entomológica do Brasil, Londrina, v.22, n.3, p.547-552, 1993.

ROSSETTO, C.J. Breeding for resistance to stink bugs. In: CONFERENCIA MUNDIAL DE INVESTI-
GACIÓN EM SOJA, 4., 1989, Buenos Aires. Actas. Buenos Aires : Orientación Gráfica Editora SRL, 1989. v.4, p.2046-2060.

ROSSETTO, C.J.; IGUE, T.; MIRANDA, M.A.C. de; LOURENÇÃO, A.L. Resistência de soja a insetos. VI. Comportamento de genótipos em relação a percevejos. Bragantia, Campinas, v.45, n.2, p.323-335, 1986.

SOSA-GOMEZ, D.R.; MOSCARDI, F. Retenção foliar diferencial em soja provocada por percevejos (Heteroptera: Pentatomidae). Anais da Sociedade Entomológica do Brasil, Londrina, v.24, n.2, p.401404, 1995.

YORINORI, J.T. Cancro da haste da soja. Londrina : Embrapa-CNPSo, 1990. 8p. (Embrapa-CNPSo. Comunicado Técnico, 80). 